\title{
Is the patient brain-dead?
}

\author{
R Agarwal, N Singh, D Gupta
}

Emerg Med J 2006;23:e5 (http://www.emjonline.com/cgi/content/full/23/1/e5). doi: 10.1136/emj.2004.019182

\section{CASE-REPORT}

A 45 year old male working as a labourer in the agricultural sector was brought to the emergency room with complaints of difficulty in opening the eye-lids, dysphagia, dysphonia, dyspnea, and progressive weakness in all four limbs, after awakening from sleep. At presentation, patient had no spontaneous respiratory efforts and was deeply cyanosed. Endotracheal intubation was performed immediately and the patient was mechanically ventilated. Physical examination revealed an afebrile patient with a heart rate of 130 beats/ minute and blood pressure of $160 / 100 \mathrm{~mm} \mathrm{Hg}$. He was comatose with absent motor responses to painful stimuli, complete ptosis, external, and internal ophthalmoplegia. Deep tendon reflexes and plantars were absent. Fang marks typical of snakebite were noted in the right middle finger. Patient was started on anti-snake venom (Haffkine Institute, Mumbai) at a dose of $100 \mathrm{~mL}$ stat followed by $50 \mathrm{~mL}$ at 6 hours, deep venous thrombosis and stress ulcer prophylaxis along with supportive care. Arterial blood gas analysis, serum electrolytes, liver, and renal function tests done were within normal limits. After initiation of ventilatory support, patient's heart rate and blood pressure returned to normal limits, and he was maintaining normal oxygen saturation on pulse oximetry, however, there was no improvement in neurological status in the next 8 hours, and a possibility of brain death secondary to prolonged hypoxia prior to hospitalisation was being considered. Patient was unresponsive to tracheal suctioning; pupillary, corneal, and oculocephalic reflexes were absent and the cold caloric test was negative. However, approximately 12 hours after presentation, patient was noted to have triggered breaths on the ventilator and in the next 72 hours, patient had recovery of all the neurological functions. He was extubated and discharged with no neurological sequelae.

\section{DISCUSSION}

Neuroparalytic snakebite is a common emergency in the tropics especially after the onset of monsoon. Patients present with acute neuroparalysis and in many cases the history of snakebite is not forthcoming as krait bites are painless. ${ }^{1}$ However, the onset of rains is a typical setting for snakebite in the tropics, and although serological methods provide objective assessment of the specific venom involved, the emergency physician can make a reasonable diagnosis based on the history of snakebite or the presence of fang marks. ${ }^{1}$

Neuromuscular paralysis in snake bite occurs as a result of blockade of neuromuscular transmission. Toxins from cobra venom act mainly post-synaptically whereas those of krait venom act mainly pre-synaptically. ${ }^{2}$ The time lag between the bite and onset of paralysis is usually 4-12 hours. The earliest manifestation is ptosis followed by external ophthalmoplegia. Paralysis then progresses to involve muscles of palate, jaw, tongue, larynx, neck, and muscles of deglutition-usually but not strictly in that order. ${ }^{3}$ The proximal muscles of the limbs are involved earlier than distal, and there can be complete quadriplegia and 'locked-in' state. Patients with acute ventilatory failure are categorised as severe envenomation. Recovery starts in the reverse order and the median time of onset for recovery of respiratory failure is 2 days. ${ }^{4}$ Patients, like the one we have presented, with 'locked-in' state and absent pupillary reflexes are uncommon. ${ }^{5}$ Internal ophthalmoplegia seen in these patients can plausibly be attributed to the autonomic dysfunction. In our hospital, patients with suspected snake envenomation are treated empirically and observed for 48 hours, while being investigated for other causes.

It is important that emergency physicians recognise the 'locked-in' syndrome, so as to prevent the dangerous error of diagnosing brain-death. The diagnosis of brain-death includes documentation of coma, absence of brain-stem reflexes, and apnea in the absence of conditions that mimic brain death like severe electrolyte and acid-base disturbances, drug intoxication, neuromuscular blocking agents, etc. ${ }^{6}$ Infact, confirmatory tests like cerebral angiography, electroencephalography, etc, are recommended in situations like 'locked-in' syndrome, where a misdiagnosis of brain death is possible. ${ }^{6}$

Anti-snake venom (ASV) is a specific antidote to snake venom actions, however, there are no clear guidelines on the optimal dose in management of patients with severe envenomation and doses as high as $1400 \mathrm{~mL}$ have been used empirically in the hope of early recovery. ${ }^{7}$ Some studies have addressed the issue of ASV dosage, but not specifically in patients with severe neuroparalytic envenomation. ${ }^{89}$ Moreover, it is not clear whether there is any use of ASV once neuroparalysis has already set in, and there are reports of patients with severe envenomation who have recovered without the use of ASV. ${ }^{310}$ In our institute, we presently use a protocol of a total dose of $150 \mathrm{~mL}$ of ASV in patients with severe neuroparalytic envenomation. The use of ASV is generally safe and only rarely have fatalities been reported. The incidence of reactions to ASV has varied from $4-81 \%$. The reactions can range from pyrogenic reactions (mild) to anaphylactic shock (severe) $)^{11}$ and can be prevented by premedication with subcutaneous adrenaline, intravenous hydrocortisone, and anti-histamines. ${ }^{12}$

In conclusion, patients with unexplained neuroparalytic syndrome even in the absence of history of snake bite, in areas where snake bites are endemic, should attract the attention of the emergency room physicians of the possibility of elapid snake bite. Early and energetic therapy even in the most severe cases is associated with excellent outcomes.

\section{Authors' affiliations \\ R Agarwal, N Singh, D Gupta, Department of Pulmonary Medicine, PGIMER, Chandigarh, India}

Correspondence to: Dr Ritesh Agarwal, Senior Resident, Department of Pulmonary Medicine, Postgraduate Institute of Medical Education and Research, Chandigarh 160012, India; drritesh1@rediffmail.com

Accepted for publication 17 September 2004

\section{REFERENCES}

1 Warrell DA and international panel of experts. WHO/SEARO Guidelines for the clinical management of snake bites in the Southeast Asian region. Southeast Asian J Trop Med Public Health 1999;30(Suppl 1):1-85. 
2 Harris JB. Snake venoms in science and clinical medicine 3. Applied immunology in snake venom research. Trans $R$ Soc Trop Med Hyg 1989;83:745-47.

3 Sethi PK, Rastogi JK. Neurological aspects of ophitoxemia (Indian krait) - a clinical-electromyographic study. Indian J Med Res $1981 ; 73: 268-276$.

4 Seneviratne U, Dissanayake S. Neurological manifestations of snake bite in Sri Lanka. J Postgrad Med 2002;48:275-79.

5 Pawar DK, Singh H. Elapid snakebite. Br J Anesth 1987;59:385-387.

6 Wijdicks EFM. The diagnosis of brain-death. N Engl J Med 2001;344:1215-1221.

7 Agrawal PN, Aggarwal AN, Gupta D, et al. Management of respiratory failure in severe neuroparalytic snake envenomation. Neurol India $2001 ; 49: 25-28$
8 Tariang DD, Philip PJ, Alexander G, et al. Randomized controlled trial on the effective dose of anti-snake venom in cases of snake bite with systemic envenomation. J Assoc Physicians India 1999;47:369-372.

9 Paul V, Pratibha S, Prahlad KA, et al. High-dose anti-snake venom versus lowdose anti-snake venom in the treatment of poisonous snake bites- a critical study. J Assoc Physicians India 2004;52:14-17.

10 Bomb BS, Roy S, Kumawat DC, et al. Do we need anti-snake venom for management of elapid ophitoxemia? J Assoc Physicians India 1996;44:31-33.

11 Gawarammana IB, Kularatne SAM, Dissanayake WP, et al. Parallel infusion of hydrocortisone \pm chlorpheniramine bolus injection to prevent acute adverse reactions to antivenom for snakebites. A randomized, double-blind, adverse reactions to antivenom for snakebites. A random
placebo-controlled study. Med J Aust 2004;180:20-23.

12 Cheng AC, Winkel KD. Antivenom efficacy, safety and availability: measuring smoke. Med J Aust 2004;180:5-6. 